DOI: $10.4274 /$ tpa.46.17

\title{
Yenidoğan döneminde nadir bir solunum sıkıntısı nedeni: posterior mediyastinal gastroenterik kist
}

\section{A rare cause of respiratory distress in newborn: posterior mediastinal gastroenteric cyst}

\author{
Erdal Taşkın, Kenan Özcan*, Mehmet Satar*, Nejat Narlı*, Ferda Özlü* , Hacer Yapıcıoğlu* \\ Fırat Üniversitesi Tıp Fakültesi, Çocuk Sağı̆̆ı ve Hastalıkları Anabilim Dalı, Yenidoğan Bilim Dalı, Elazı̆̆, Türkiye \\ *Çukurova Üniversitesi Tıp Fakültesi, Çocuk Sağı̆ı̆ı ve Hastalıkları Anabilim Dalı, Yenidoğan Bilim Dall, Adana, Türkiye
}

\section{Özet}

Yenidoğan döneminde mediyastinal enterik kist nadiren görülür. Çoğunlukla bulgu vermez. En sık solunum güçlüğü ile kendini belli eder. Mediyastinal kist omuz anomalilerinin eşlik ettiği bir durumdur ve enterik özellik gösterir. Tanısı esas olarak histolojik bulgularla konulur. Bu yazıda doğum öncesi ultrasonografik incelemede akciğerde kistik adenoid malformasyon tanısı almış ve dört günlükken solunum sıkıntısı gelişmiş bir mediyastinal gastroenterik kist olgusu sunulmuştur. Yenidoğan döneminde mediyastinal gastroenterik kistin tanı ve yönetiminin tartışılması amaçlanmıştır. (Türk Ped Arş 2011; 46: 90-2)

Anahtar sözcükler: Enterik kist, solunum sıkıntısı, yenidoğan

\section{Summary}

Presentation of mediastinal enteric cysts are rare during neonatal period. They are mostly asymptomatic. The commonest mode of presentation in neonatal period is repiratory distress. Basically, diagnosis of enteric cyst is histologically, for all that vertebral anomalies associated with posterior mediastinal cyst is property of enteric cyst. $0-24 \mathrm{~h}$ male patient who diagnosed cystic adenoid malformation of lung on prenatal ultrasonographic examination developed respiratory distress at day 4 of life after birth. Investigations revealed a well defined gastroenteric cyst in the posterior mediastinum with vertebral anomalies. The purpose of this case report is to highlight the clinical diagnosis and management of a neonate with posterior mediastinal enteric cyst. (Turk Arch Ped 2011; 46: 90-2)

Key words: Enteric cyst, newborn, respiratory distress

\section{Giriş}

Sindirim sisteminin duplikasyon kisti ağızdan anüse kadar herhangi bir yerde gelişebilir (1). Sindirim sistemi duplikasyon kistlerinin \%20'si toraksta ortaya çıkar. Duplikasyon kistlerinin büyük bir bölümü çocukluk çağında tespit edilir (2). Foregut kistleri tüm mediyasten tümörlerinin \%10'unu oluşturur $(3,4)$. Foregut kistlerinin bronkojenik, intramural özofageal ve enterik olmak üzere üç tipi tanımlanmıştır. Tanı esas olarak histolojik olmakla birlikte omurga anomalilerinin eşlik ettiği mediyastinal kist enterik özellik gösterir. Yenidoğan döneminde enterik kistin ortaya çıkışı nadirdir ve çoğunlukla bulgu vermez. En sık solunum güçlüğü ile kendini belli eder (1).

Burada yenidoğan dönemi solunum sıkıntısının nedenleri arasında çok nadir tanımlanan mediyastinal enterik kistin tanısı ve yönetimi literatür eşliğinde tartışıldı.

\section{Olgu sunumu}

Aralarında akrabalık olmayan 43 yaşında sağlıkı baba ile 35 yaşında preeklamptik annenin yedinci gebeliğinden yaşayan dördüncü çocuk olarak miadında sezaryen ile

Yazışma Adresi/Address for Correspondence: Dr. Erdal Taşkın, Fırat Üniversitesi Tıp Fakültesi, Çocuk Sağı̆̆ğ ve Hastalıkları Anabilim Dalı, Yenidoğan Bilim Dalı, Elazığ, Türkiye E-posta: drerdaltaskin@yahoo.com Geliş Tarihi/Received: 13.10.2009 Kabul Tarihi/Accepted: 22.03.2010 
doğurtuldu. Apgar skoru birinci dakikada 5, beşinci dakikada 8 idi. Doğum öncesi dönemde 34. gebelik haftasındaki ultrasonografik incelemede sol akciğerde kistik adenoid malformasyon ön tanısı olan erkek bebek doğum sonrası Yenidoğan Yoğun Bakım Birim'ine alındı. Fizik incelemede doğum ağırlığı $3400 \mathrm{gr}(\% 50-75$ p), baş çevresi $35 \mathrm{~cm}$ (\%50-75 p), boyu $49 \mathrm{~cm}$ (\%50-75 p), nabız 152 atım/dak, kan basıncı 78/32 mm Hg idi. Göğüs muayenesinde sol akciğer alanlarında sağa göre hafif ekspiryumun uzaması dışında özellik yoktu. Kalp sesleri normaldi, periferik nabızlar kalp sesleri ile eş zamanlı olarak ele geldi. Karın muayenesinde organ büyüklüğü yoktu ve orogastrik tüpün mideye geçişi vardı. Başlangıç arteryel kan gazı pH: 7,35, PaCO2: $43 \mathrm{mmHg}, \mathrm{PaO}_{2}: 71 \mathrm{mmHg}, \mathrm{HCO}_{3}: 19 \mathrm{mmol} / \mathrm{L}$ ve oksijen doygunluğu \%95 idi. Tam kan sayımı ve sodyum, potasyum, üre, kreatinin, kalsiyum ve kan şekerini içeren serum biyokimya değerleri normal sınırlar içerisindeydi.

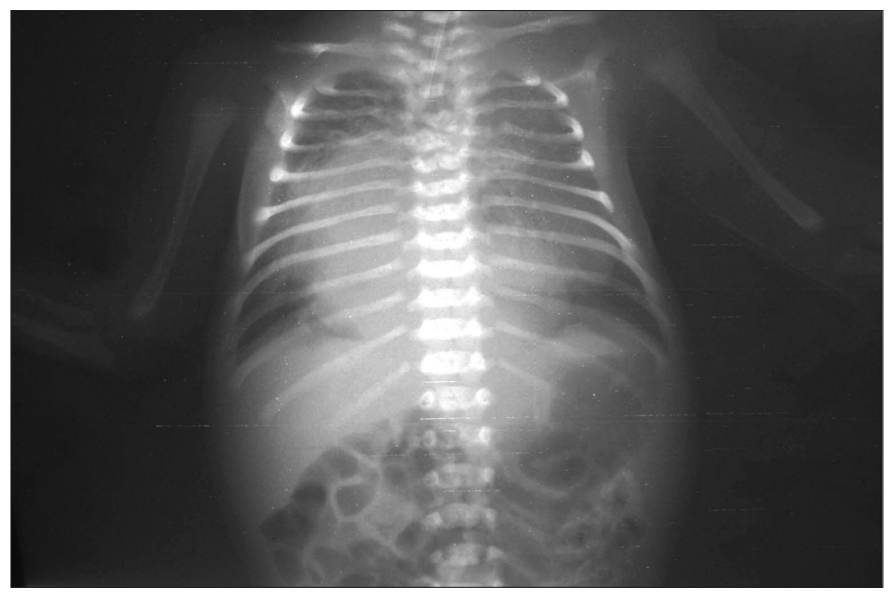

Resim 1. Göğüs grafisinde sağ ve sol parakardiyak yerleşimli, konsolide, düzgün sınırlı kitle görünümü ve T3, T4, T5 omurlarda korpus defekti

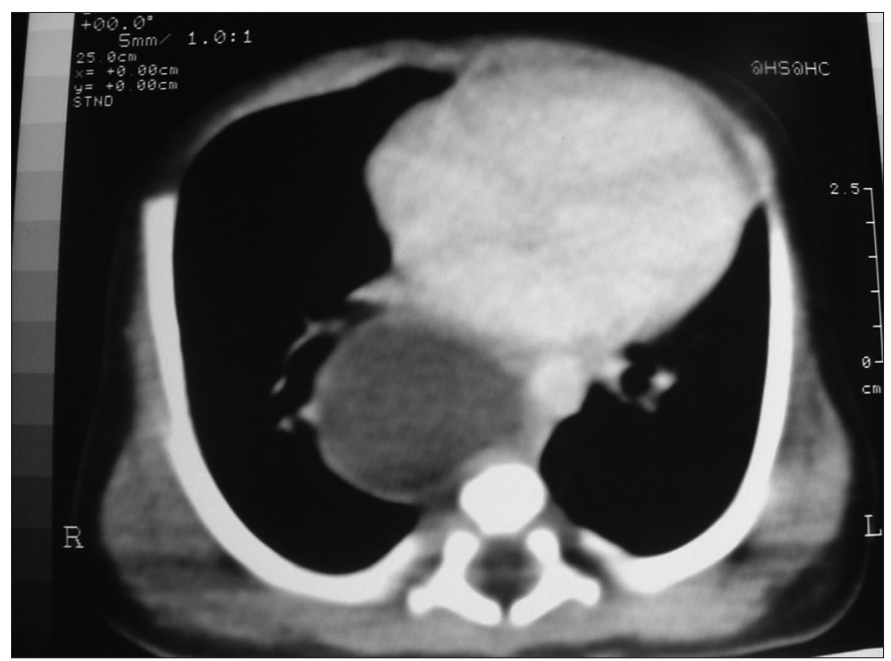

Resim 2. Göğsün bilgisayarlı tomografik incelemesinde trakeal çatallaşmasınınn üstüne kadar uzanan, sağda trakea, özofagus ve aortu öne doğru iten kistik kitle görünümü
Göğüs grafisinde sağ ve sol parakardiyak konsolide düzgün kenarlı kitle görünümü saptandı. T3, T4, T5 vertebralarda korpus defekti dikkati çekti (Resim 1). Göğsün bilgisayarlı tomografik incelemesinde diyaframın hemen üstünden başlayarak yukarıda trakeal çatallaşmasının üstüne kadar uzanan, ağırlıklı olarak sağda trakea, özofagus ve aortu öne doğru iten büyük bir kistik kitle görünümü mevcut idi. Kistin iki bölümden oluştuğu tespit edildi (Resim 2). Özofagogramda özofagus $1 / 3$ alt kısmı öne ve hafif sola doğru yer değiștirmiş ve trakeaya bası yapmaktaydı. Ekokardiyografik incelemede kalbin arkasında sol atriyuma komşu 3,5x5 $\mathrm{cm}$ çaplarında kistik oluşum saptandı. Yaşamının ilk 4. gününe kadar herhangi bir sorunu olmayan hastanın aynı gün solunum sıkıntısı gelişti. Aynı zamanda bakılan kan gazında $\mathrm{pH}: 7,18, \mathrm{PaCO}_{2}: 86 \mathrm{mmHg}, \mathrm{PaO}_{2}: 47 \mathrm{mmHg}, \mathrm{HCO}_{3}$ : 14,9, oksijen doygunluğu \%76 idi. Hasta entübe edilerek mekanik ventilatör desteğine alındı. Yedinci gün ekstübe edildi. Yaşamın sekizinci günü hasta ameliyata alındı. Tümüyle sağ posterior mediyastenden yana doğru uzanım gösteren kalınca duvarlı, üzerindeki plevranın da kısmen kalınlaşmış olduğu kistik yapı tespit edildi. Kitle, duvarındaki enflamasyon nedeniyle çevre dokulara yapışıktı. Kitlenin içerisinden koyu kıvamlı, hafif mukoid içerikli kirli sarı renkli 10 cc sıvı boşaltıldı. Kitle nedeniyle daha önce sönmüş olan akciğer alanları havalanmaya başladı. Kistin orta hatta omur cismine fibrotik bant ile yapışık olduğu gözlendi. Patolojik incelemede kistik yapı içerisinde mide epitel ve ince bağırsak mukozasıyla döşeli olduğu gözlendi, kist duvarında düz kas dokusu görüldü, epitelde yer yer ülseratif iltihap dikkati çekti, sonuç olarak enterik kist ile uyumlu bulundu.

Ameliyat sonrası hastanın solunum sıkıntısı hızla geriledi ve 10 gün sonra hasta taburcu edildi. Taburcu edildikten sonraki bir yıllık izleminde herhangi bir komplikasyon veya sorun olmadl.

\section{Tartışma}

Yenidoğan ve erken çocuklukta mediyastinal kist nadirdir. Arka mediyastinal kist sıklı̆ı̆ın tüm mediyastinal kitleler içerisinde \%7 olduğu bildirilmiştir (4). Arka mediyastendeki enterik kist çoğunlukla bulgu vermez. Kist solunum yolu ile ilişkili ise solunum güçlüğü gelişebilir. Kist enfekte olabilir ve sepsis özellikleri göstererek solunum komplikasyonlarına neden olabilir. Olgumuzda kistik sıvıda iltihabi doku hücreleri görülmesi literatür ile uyumludur (5).

Enterik kist özofageal duplikasyon ve nöroenterik kistleri içeren "foregut" gelișim bozukluğudur (6). "Nöroenterik kist" vertebral veya nöral anomalilere ikincil notakord bağlantısının foregut ile bağlantısının kaybını tanımlamak için kullanılır. Kistin fibröz bir bağla omurlara bağlı olduğu görülebilir (1). Bizim olgumuzda da kist omur cismine bağlı idi ve T3, T4, T5 omurlarda korpus defekti vardı.

Nöroenterik kistler sıklıkla hem nöral ve hem de mide mukozası da olan enterik dokuyu içerir. Nöroenterik kistlerin yaklaşık \%90'ı arka mediyastende görülür. Olguların 
\%50'sine skolyoz, ön spina bifida, hemivertebra ve kelebek vertebra gibi vertebral anomaliler eşlik eder (7). Özofageal duplikasyon kistlerinin duvarı sindirim epiteli ve bunun da \%50-60'ı mide mukoza ve pankreas dokusunu içerir. Mediyastinal enterik kist özofageal kistlerden farklı bir içeriktedir. Enterik kist genellikle mediyastenin arka sağ tarafında ve kalbin arka kısmındadır ve sıklıkla sağ hemitoraksa doğru uzanır (7). Klinik olarak kitle etkisinden dolayı solunum sıkıntısına neden olur. Bizim olgumuzda doğumdan sonra ilk dört gün herhangi bir bulgusu olmayan hastanın dördüncü günden sonra solunum sıkıntısı gelişti, yapılan incelemelerde kistin sağ hemitoraksa uzanım gösterdiği tespit edildi.

Yenidoğan ve erken çocukluk döneminde çok az sayıda arka mediyastinal enterik kist bildirilmiştir (8-10). Cerrahi öncesinde kistin tipini ayırt etmek güçtür. Gögüs grafisinde genellikle arka veya orta mediyastende tipik yerleşimli yuvarlak yumuşak doku kisti görülür. Kistin duvarı bronkojenik kist duvarından daha kalındır. Teknesyum 99 ile yapılan radyoizotop çalışması enterik kistin tanısında yararlıdır. Bilgisayarlı tomografi taraması kjstin anatomik yerleşimini belirlemek için kullanılabilir (11). Cerrahi olarak çıkarım esas tedavidir $(12,13)$.

Sonuç olarak mediyastinal enterik kistler selim olmalarına karşın komşu olduğu organlara kitle etkileri ile klinikte ciddi seyir gösterebilir ve hayatı tehdit edebilir. Doğum öncesi ultrasonografik incelemede akciğerlerde şüpheli kitle saptanan olgularda arka mediyastinal enterik kist akılda tutulmalı ve olguların doğumu yenidoğan yoğun bakım birimlerinin olduğu yerlerde yapılmalıdır. Cerrahi ekip ile iş birliği yapılarak erken dönemde uygun girişimin yapılmasının hayat kurtarıcı olduğu unutulmamalıdır.

\section{Çıkar çatışması: Bildirilmedi.}

\section{Kaynaklar}

1. Birmole BJ, Kulkarni BK, Vaidya AS, Borwankar SS Intrathoracic enteric foregut duplication cyst. J Postgrad Med 1994; 40: 228-30. (Abstract)

2. Kumar R, Jain R, Rao KM, Hussain N. Intraspinal neurenteric cysts. Report of three paediatric cases. Childs Nerv Syst 2001; 7: 584-8. (Abstract) / (Full Text) / (PDF)

3. Azzie G, Beasly S. Diagnosis and treatment of foregut duplications. Semin Pediatr Surg 2003; 12: 46-54. (Abstract) / (PDF)

4. Sethi GK, Marsden J, Johnson D. Duplication cysts of the esophagus. South Med J 1974; 67: 616-8. (Abstract) / (PDF)

5. Yadav TP, Bhardwaj M, Aggarwal S, Mohan B, Ndeswari A. Mediastinal enteric cyst infected with Salmonella typhi. Indian Pediatr 2000; 37: 667-70. (Abstract)

6. Nawaz A, Matta H, Jacobsz A, Ansari F, Al-Khouder G, AlSalem A. Intrathoracic foregut duplication cysts in neonates. Annals of Saudi Medicine 2001; 21: 206-9. (PDF)

7. King RM, Telander RL, Smithson WA, Banks PM, Han MT. Primary mediastinal tumors in children. J Pediatr Surg 1982; 17: 512-20. (Abstract) / (PDF)

8. Mam MK, Mathew S, Prabhakar BR, Paul R, Jacob S. Mediastinal enterogenic cyst presenting as paraplegia--a case report. Indian J Med Sci 1996; 50: 337-9. (Abstract)

9. Alrabeeah A, Gillis DA, Giacomantonio M, Lau H. Neurenteric cysts-a spectrum. J Pediatr Surg 1988; 23: 752-4. (Abstract) / (PDF)

10. Rammurty DV, Soans B, Mohan M, Gupta HO, Baijal VN, Kulshrestha R. Enterogenic cyst in mediastinum. Indian Pediatr 1990; 27: 1109-11. (Abstract)

11. Fernandes ET, Custer MD, Burton EM, et al. Neurenteric cyst surgery and diagnostic imaging. J Pediatr Surg 1991; 26: 108-10. (Abstract)

12. Newnham JP, Crues JV, Vinstein AL, Medearis AL. Sonographic diagnosis of thoracic gastroenteric cyst in utero. Prenat Diagn 1984; 4: 467-71. (Abstract)

13. Perek A, Perek S, Kapan M, Goksoy E. Gastric duplication cyst. Dig Surg 2000; 17: 634-6. (Abstract) / (Full Text) / (PDF) 